
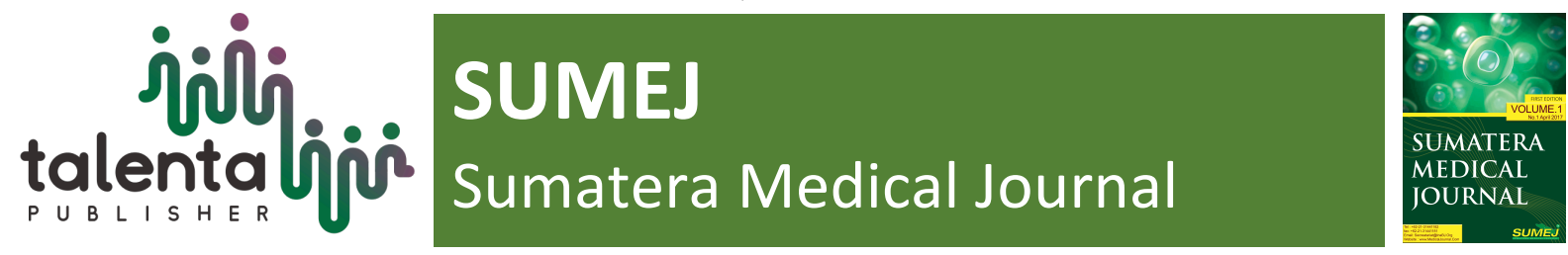

\title{
Profile of Brain Tumor Patients in 10 Hospitals in North Sumatera
}

\author{
Aldy S. Rambe ${ }^{1}$, Aida Fitri ${ }^{2}$, Tonam ${ }^{2}$ \\ ${ }^{I}$ Department of Neurology, Universitas Sumatera Utara, Adam Malik General Hospital Medan, Indonesia \\ ${ }^{2}$ Indonesia Neurological Association, Medan, Indonesia
}

\begin{abstract}
Background: Although brain tumors only 1.4\% of all tumors, high fatality rate made these tumors need special attention. In North Sumatera, there is no data on brain tumors patients profile. Objective: To determine brain tumor patients' profile in North Sumatera, Indonesia. Method: A descriptive hospital-based study with primary data which taken from September-December 2012. Result: Of 75 brain tumors patients surveyed in 10 hospitals in North Sumatera $38(50.7 \%)$ patients were male and $37(49.3 \%)$ patients were female. Mean of age was 51.45 (11-87) years old. Most of the subjects were housewifes, $26(34.7 \%)$ patients. The most common cause that brought these patients to see doctors was headache 32 (42.7\%), followed by decreased level of consciousness 17 (22.7\%). Clinical manifestations found in these patients were headache 67 (89.3\%), dizziness/vertigo 41 (54.7\%), convulsion $22(29.3 \%)$, vomitting $32(42.7 \%)$, motor dysfunction $46(61.3 \%)$, sensory dysfunction 21 (28\%), and cognitive decline $21(28 \%)$. Only 7 patients $(9.3 \%)$ had history of tumor in his/her relatives. Eighteen patients $(24 \%)$ were treated surgically and $8(10.7 \%)$ were given radiotherapy. 71 patients were alive $(94.7 \%)$ when discharged from the hospitals due to various reasons. Head CT Scan/MRI showed primary tumors in $56(74.7 \%)$ patients. Of these primary tumors 25 (44.6\%) patients were meningioma and $19(33.9 \%)$ were astrocytoma. Of $19(25.3 \%)$ patients with secondary tumor, most common primary tumor where found in the lung $11(57.9 \%)$. Conclusion: Sex the patients were equally distributed with mean of age was 51.45 (11-87) years old. The most common cause that brought these patients to seek for treatment were headache. Most of these patients were treated conservatively. The most common head CT Scan/MRI findings showed primary tumors.
\end{abstract}

Keyword: Brain Tumor, North Sumatera, Profile

Received 30 May 2018 | Revised 10 July 2018 | Accepted 20 September 2018

\footnotetext{
*Corresponding author at: Faculty of Medicine, Jalan Doktor Mansyur No.5 Kampus USU Padang Bulan, Medan, Sumatera Utara 20155
} 


\section{Introduction}

The Brain tumors covered only $1.4 \%$ of all malignancy, however high fatality rate and traumatic experience was unavoidable for patients and family members made these brain tumors need a particular attention[1]. The treatment of patients with tumors was different from another malignancy [2].

In adults, secondary tumors are ten times more common than primary tumors, whereas the incidence of primary tumors reached 14.4 / 100,000 population with glioma as the most frequent types $(40 \%)[1-3]$.

Histopathologically, tumors were classified into: neuroepithelial tissue tumors (gliomas, including astrocytoma, anaplastic astrocytes, glioblastoma, oligodendroglioma, and ependimoma), meningeal tumor (meningioma and hemangioblastoma), germ cell tumors, and sellar tumors (pituitary tumors and craniofaringiomas) [4].

\section{Methodology}

This study was a descriptive study with the cross-sectional method of brain tumor patients who were treated at 10 hospitals in North Sumatra Province. Data collection was conducted from September-December 2012 by neurologists who served in the hospitals of this study.

The data analysis was done by using data processing software and Statistical Package for Social Sciences (SPSS).

\section{Results and Discussion}

Description The data collection was collected on brain tumor patients were treated at 10 hospitals in North Sumatra, obtained a total of 75 research subjects for descriptive study. This study showed 38 (50.7\%) male patients and 37 (49.3\%) female patients. Male patients with brain tumors $(60.74 \%)$ are more than female patients (39.26\%) [4,5]. The mean age in this study was 51.45 (11-87) years. In the United States, the mean age at diagnosis in patients with primary tumors is 57 years [4].Although tumors can occurs at any age, however it is more common in late middle age [6].

Most of subject occupations for this study were housewives 26 (34.7\%). Table distribution of subjects' medical condition (Table 2) showed the most commons chief complaints were: headache 32 (42.7\%), followed by decreased level consciousness 17 (22.7\%), hemiparesis $12(16 \%)$, and seizures $11(14.7 \%)$. Clinical manifestations were experienced by patients: headache 67 (89.3\%), dizziness / vertigo 41 (54.7\%), seizures 22 (29.3\%), vomiting 32 (42.7\%), motor disorders 46 (61.3\%), sensory disturbances 21 (28\%), Cognitive decline 21 (28\%), and decreasing level consciousness $17(22.7 \%)$. Headache is the first symptom found in approximately $30-40 \%$ of 
brain tumor patients $[4,6]$. Seizures occur in $33 \%$ of patients with brain tumors [6]. Seizure is the earliest symptom of brain tumors in $25 \%$ of cases and more than $35 \%$ of cases at an advanced stage [4]. Vomiting was found in $30 \%$ of cases and commonly accompanies with headache [4]. Patients who had a family history of brain tumors were only 7 (9.3\%). Patients were treated surgically 18 (24\%) and were given radiotherapy 8 (10.7\%), 71 patients were alive (94.7\%) at the end of data collection.

Based on the CT Scan/MRI head: primary tumors were 56 patients $(74.7 \%)$, secondary tumors were 19 patients $(25.3 \%)$. On the secondary tumors, most metastases from the lung $11(57.9 \%)$ cases, while the primary tumor: meningioma 25 (44.6\%) and astrocytoma 19 (33.9\%). Based on the Fisher's research, et al. it was found that Primary brain tumors (80\%) and secondary (20\%). 4 Brain metastases was found in $20-40 \%$ of cancer patients and have $10: 1$ ratio with a primary brain tumors $[7,8]$. The typed of cancer most commonly metastasizes to the brain is lung cancer, is 30 $60 \%$ of brain metastases $[7,8]$. In the US 35,000 new cases of brain tumors was found each year, the most common tumor type is meningioma (39.26\%) [4]. In Japanese studies, 32\% of the primary brain tumors was meningioma [6]. Astrocytoma was about $35 \%$ of primary brain tumors $[5,6]$.

The limitation of this study is neuroimaging scans done by different tools and interpreted by different radiologists, so that the accuracy of diagnostic in radiology was vary, the diagnosis definitely cannot do biopsy and the accurate result could not be obtained because the patient was not followed by the treatment of the disease after getting out from the hospital.

Table 1. Characteristic Demographic Distribution of Research Study

\begin{tabular}{lcc}
\hline $\begin{array}{l}\text { Demographic } \\
\text { Characteristic }\end{array}$ & Total & Percentage \\
\hline Sex & 38 & 50.7 \\
Male & 37 & 49.3 \\
Female & 26 & \\
Occupation & 26 & 34.7 \\
Housewife & 17 & 22.7 \\
Private & 13 & 17.3 \\
Jobless & 8 & 10.7 \\
Etc. & 6 & 8.0 \\
Pensiunan & 5 & 6.7 \\
Public civil servant & & \\
\hline
\end{tabular}




\begin{tabular}{lcr}
\hline Clinical condition & Total & Percen \\
\hline Main Complaint & 32 & 42.7 \\
Headache & 17 & 22.7 \\
Decresing level of consciousness & 12 & 16.0 \\
Convulsion & 11 & 14.7 \\
Hemiparesis & 2 & 2.6 \\
Visual dysfunction & 1 & 1.3 \\
Vertigo &
\end{tabular}

\section{Consciousness}

Conscious

Decreasing level of

consciousness

\section{Headache}

Yes

No

\section{Dizziness/vertigo}

Yes

No

\section{Convulsion}

Yes

22

29.3

No

Vomiting

Yes

32

43

No

Motor dysfunction

Yes

No

Sensory dysfunction

Yes

No

Congitive dysfunction

Yes

7

No

Family background

Yes

No

41

34

45.3

53

70.7

46

61.3

29

38.7

21

28.0

54

72.0

68

28.0

72.0 


\section{Operation}

$\begin{array}{lcc}\text { Yes } & 8 & 24.0 \\ \text { No } & 67 & 76.0 \\ \text { Radiotherapy } & & \\ \text { Yes } & 8 & 10.7 \\ \text { No } & 67 & 89.3\end{array}$

\section{OutCome}

$\begin{array}{lcc}\text { Alive } & 71 & 94.7 \\ \text { Dead } & 4 & 5.3 \\ \text { Result CT Scan/MRI } & & \\ \text { Primer } & 56 & 74.7 \\ \text { Metastasis } & 19 & 25.3\end{array}$

\section{Conclusion}

This is amounts of male patients was compatible with female patients. The mean age was 51.45 (11-87) years. The most frequent main complaint was headache. During the first checked, most of the patients were conscious. Most of the patients got conservatives therapy and the result was alive at the time the patient got out of the hospital with various reasons. Based on CT Scan/MRI head result, most of them showed the imagining of primary tumor (Meningioma and astrocytoma). The certain diagnosis was not obtained because biopsy was not performed.

\section{REFERENCES}

[1] M.L. Bondy, R. El-Zein, M. Wrensch, Epidemiology of brain cancer, Principles of Neurooncology. (2005) 3-16.

[2] S.A. Grossman, General Care of Patients with Cancer Involving the Central Nervous System, in: Neuro-Oncology of CNS Tumors, Springer, 2006: pp. 687-696.

[3] Z. Dorai, R. Sawaya, W.A. Yung, Brain metastasis, in: Neuro-Oncology of CNS Tumors, Springer, 2006: pp. 303-323.

[4] J.L. Fisher, J.A. Schwartzbaum, M. Wrensch, J.L. Wiemels, Epidemiology of brain tumors, Neurologic Clinics. 25 (2007) 867-890.

[5] M.L. Bondy, M.E. Scheurer, B. Malmer, J.S. Barnholtz-Sloan, F.G. Davis, D. Il'Yasova, C. Kruchko, B.J. McCarthy, P. Rajaraman, J.A. Schwartzbaum, Brain tumor epidemiology: consensus from the Brain Tumor Epidemiology Consortium, Cancer. 113 (2008) 1953-1968.

[6] L.M. DeAngelis, P.H. Gutin, S.A. Leibel, J.B. Posner, Intracranial tumors: diagnosis and treatment, CRC Press, 2003.

[7] D. Schiff, I. Arrillaga, P.Y. Wen, Cancer Neurology in Clinical Practice: Neurological Complications of Cancer and Its Treatment, Springer, 2017.

[8] J.-C. Tonn, M. Westphal, J.T. Rutka, S.A. Grossman, Neuro-oncology of CNS tumors, Springer Science \& Business Media, 2006. 